\title{
Impact of Direct Soil Moisture and Revised Soil Moisture Index Methods on Hydrologic Predictions in an Arid Climate
}

\author{
Milad Jajarmizadeh, ${ }^{1}$ Sobri bin Harun, ${ }^{1}$ Shamsuddin Shahid, ${ }^{1}$ \\ Shatirah Akib, ${ }^{2}$ and Mohsen Salarpour ${ }^{1}$ \\ ${ }^{1}$ Department of Hydraulics and Hydrology, Faculty of Civil Engineering, Universiti Teknologi Malaysia, 81310 Skudai, Johor, Malaysia \\ ${ }^{2}$ Department of Civil Engineering, Faculty of Engineering, University of Malaya, 50603 Kuala Lumpur, Malaysia
}

Correspondence should be addressed to Milad Jajarmizadeh; milad_jajarmi@yahoo.com

Received 15 June 2014; Revised 18 August 2014; Accepted 25 September 2014; Published 15 October 2014

Academic Editor: Klaus Dethloff

Copyright (C) 2014 Milad Jajarmizadeh et al. This is an open access article distributed under the Creative Commons Attribution License, which permits unrestricted use, distribution, and reproduction in any medium, provided the original work is properly cited.

\begin{abstract}
The soil and water assessment tool (SWAT) is a physically based model that is used extensively to simulate hydrologic processes in a wide range of climates around the world. SWAT uses spatial hydrometeorological data to simulate runoff through the computation of a retention curve number. The objective of the present study was to compare the performance of two approaches used for the calculation of curve numbers in SWAT, that is, the Revised Soil Moisture Index (SMI), which is based on previous meteorological conditions, and the Soil Moisture Condition II (SMCII), which is based on soil features for the prediction of flow. The results showed that the sensitive parameters for the SMI method are land-use and land-cover features. However, for the SMCII method, the soil and the channel are the sensitive parameters. The performances of the SMI and SMCII methods were analyzed using various indices. We concluded that the fair performance of the SMI method in an arid region may be due to the inherent characteristics of the method since it relies mostly on previous meteorological conditions and does not account for the soil features of the catchment.
\end{abstract}

\section{Introduction}

The soil and water assessment tool (SWAT) is a semiphysical and semiempirical modeling tool developed by the United States Department of Agriculture (USDA) [1]. SWAT can be developed for rainfall-runoff simulation with different short-term and long-term objectives, for example, prediction of stream flow and sedimentation, identification of best management practices (BMP), and planning water resources of large and complex watersheds [2-4]. In recent years, the application of SWAT has increased rapidly as a modeling tool for various hydrological processes under different climate conditions around the world. It is anticipated that SWAT will continue to evolve in response to the need for improved understanding of key hydrological processes [5].

SWAT uses the soil conservation services' curve number (SCS-CN) to estimate the volume of stream flow. The SCS-CN method uses soil classes and land-use/landcover information for the prediction of runoff [6]. The method separates effective rainfall from total rainfall by using the water balance concept [7]. The SCS-CN method is used extensively for consecutive flow simulation for long-term runoff analysis [8]. It can also be used for optimal estimation of surface runoff in ungauged watersheds [9]. Due to its feasibility and uncomplicated characteristics, the method has been integrated into several hydrological models [7]. SWAT is one such hydrological modeling tool that uses the SCS$\mathrm{CN}$ method to predict water flows in large and ungauged watersheds.

SWAT uses two methods for the calculation of the retention parameter and estimation of the runoff curve number. One method is related to soil profile water content, and it is known as the Soil Moisture Condition II (SMCII) method [10]. The other method is related to accumulated plant evapotranspiration. Usually, SMCII method predicts much more runoff in shallow and/or low storage soil areas [11]. In other words, this method simulates stream flows in rivers or channels by overestimation, especially for soil types and land use that involve high-permeability mixtures of sand and silt. The Revised Soil Moisture Index (SMI) method was 
developed for SWAT to account for the daily curve number as a function of plant evapotranspiration. This method is less dependent on soil storage and more dependent on the previous climate [12].

In recent years, extensive research has been conducted to examine the capability of $\mathrm{CN}$ methods and/or to develop modified $\mathrm{CN}$ methods according to local conditions. A group of studies focused on exploring the behavior of the SMCII and SMI methods in the SWAT model for flow prediction and the contribution of the regional climate on stream flow [12-17]. The results showed that the use of SMI method in SWAT model yielded promising performance in calculating discharges from plant evapotranspiration and the previous climate. Kim et al. [7], White et al. [14], and Easton et al. [15] proposed new methods for high slopes and monsoon climates to explore the optimal estimation of flood events. Their results indicated that modification of the SMCII method was required for reliable simulation of stream flow in monsoon climates in order to avoid overprediction of extreme events, such as floods. Therefore, Kim and Lee [16] used weighted average curve number to improve the poor performance of SWAT in predicting extreme rainfall events. The performance of SMI method in SWAT has also been assessed for simulating stream flow in a low-gradient, forested climate, and it has been reported that the SMI method can overcome the complexities of calculating stream flow [17]. However, the performance of the SMI method is still unknown in a thin forest climate, so it is not known whether it is viable for practical use in hydrological sciences in such a climate [17]. This emphasizes the need for additional research on exploring the behavior of the SMCII and SMI methods in the SWAT model in various climates, such as arid and semiarid zones $[12,13]$.

During the past few decades, SWAT has been used in different catchments of Iran for various purposes. Most of the studies addressed the impact of land-use changes, water resource management, pollution tracking, impact of effective precipitation on stream flow, and the impact of global climate change on river discharge [18-25]. Generally, all the studies used the SMCII method (the conventional method) for calibration of the SWAT model, and the impact of the SMI method has not been reported for discharge simulation. Moreover, most of the studies mentioned above used manual calibration.

This research is a supplementary concept for developing a SWAT model in Roodan Plain by Jajarmizdeh et al. [26, 27]. The overall objectives of the study are to evaluate the performance of SMI and SMCII methods in SWAT for stream flow in a large arid catchment in order to have a better understanding of the sensitive parameters and the behavior of SWAT in such climate. Furthermore, the present study includes the application of a semiautomatic calibration algorithm and uncertainty analysis for the SWAT model to compare the performances of the SMCII and SMI methods in approximating discharges.

\section{Methodology}

SWAT consists of several different modules, including simulation of weather, crop growth, evapotranspiration, runoff, soil erosion, and transport of nutrients and pesticides. SWAT divides a watershed into subcatchments, and the subcatchments are divided into hydrological response units, which are individual combinations of soil, land cover, and slope. In SWAT, surface runoff and pollutants from hydrological response units (HRUs) within a subcatchment are routed to the catchment reach by using a lumped procedure for simulating the runoff of the catchment. Two methods are available in SWAT for estimating runoff, that is, the modified NRCSCN method (or Direct Soil Moisture (SMCII)) method and the Revised Soil Moisture Index (SMI) method.

The SMCII method is based on the runoff curve number (CN) method [6], which uses watershed land-cover and soil characteristics to estimate direct runoff from a rainfall event [13]. CN values in this model are calculated on a daily basis using soil retention parameter values as a proxy for soil water status characterized by field capacity, wilting point, and saturation water content. When water content varies with the soil profile, the following equation is used to calculate the retention parameter:

$$
S=S_{\max } \cdot\left(1-\frac{\mathrm{SW}}{\left[\mathrm{SW}+\exp \left(w_{1}-w_{2} \cdot \mathrm{SW}\right)\right]}\right),
$$

where $S$ is the retention parameter for a given day ( $\mathrm{mm}), S_{\max }$ is the maximum value the retention parameter can achieve on any given day ( $\mathrm{mm}), \mathrm{SW}$ is the soil water content of the entire profile, excluding the amount of water held in the profile at wilting point $(\mathrm{mm})$, and $w_{1}$ and $w_{2}$ are shape coefficients. The shape coefficients can be obtained by solving (1) with the following assumptions: (a) the retention parameter for moisture condition I curve number corresponds to wilting point of soil profile water content; (b) the retention parameter curve number for moisture condition III corresponds to field capacity soil profile water content; and (c) the soil has a curve number of 99 when completely saturated. This means that the retention parameter is 2.54 as the soil is fully saturated [1]. Based on the above assumptions, (2) can be obtained by solving (1) to derive shape coefficients that reflect the nonlinearity of water content in the soil layers as follows:

$$
\begin{gathered}
w_{1}=\ln \left(\frac{\mathrm{FC}}{1-S_{3} \cdot S_{\max }^{-1}}-\mathrm{FC}\right)+w_{2} \cdot \mathrm{FC} \\
w_{2}=\left(\ln \left(\frac{\mathrm{FC}}{1-S_{3} \cdot S_{\max }^{-1}}-\mathrm{FC}\right)-\ln \left(\frac{\mathrm{SAT}}{1-2.54 \cdot S_{\max }}-\mathrm{SAT}\right)\right) \\
\times(\mathrm{SAT}-\mathrm{FC})^{-1},
\end{gathered}
$$

where $w_{1}$ is the first shape coefficient, $w_{2}$ is the second shape coefficient, FC is the amount of water in the soil profile at field capacity $(\mathrm{mm}), S_{3}$ is the retention parameter for the moisture condition III curve number, $S_{\max }$ is the retention parameter for the moisture condition I curve number, SAT is the amount of water in the soil profile when completely saturated $(\mathrm{mm})$, and 2.54 is the retention parameter value for curve number 99.

The Revised Soil Moisture Index (SMI) method is related to the continuous $\mathrm{CN}$ approach. The curve number is 
TABLE 1: General soil features of Roodan watershed.

\begin{tabular}{lccccc}
\hline Code name & Hydrologic group & Texture & Clay-silt-sand $(\%)$ & Area $\left(\mathrm{km}^{2}\right)$ & $\%$ watershed area \\
\hline 3328 & D & Clay-loam & $37-38-25$ & 6152.3 & 59.5 \\
3128 & C & Loam & $20-33-47$ & 1288.5 & 12.5 \\
3508 & D & Loam & $26-39-35$ & 1194.5 & 11.67 \\
3631 & D & Clay & $41-39-19$ & 1058.2 & 10.2 \\
3552 & D & Loam & $27-39-34$ & 624.8 & 6 \\
3264 & D & Salty & $5-25-70$ & 6.5 & 0.06 \\
\hline
\end{tabular}

modified by replacing the five-day antecedent rainfall with a Soil Moisture Index as part of a daily water-yield model. The SMI is driven by rainfall, runoff, and lake evaporation [13]. By calculating the daily $\mathrm{CN}$ as a function of plant evapotranspiration, the value of $\mathrm{CN}$ becomes less dependent on soil storage and more dependent on antecedent climate. In the SMI, the retention parameter is updated at the end of every day according to the following equation:

$$
S_{t}=S_{t-1}+\mathrm{PET}_{t} \exp \left(\frac{-B S_{t-1}}{S_{\max }}\right)-p+Q,
$$

where $S_{t}$ is the retention at the present time step, $S_{t-1}$ is the retention at the previous time step, $\mathrm{PET}_{t}$ is the potential evapotranspiration for the day $t, B$ is the depletion coefficient, $P$ is the rainfall depth on the day, $Q$ is the runoff depth, and $S_{\max }$ is the maximum value of the retention. The concept of SMI method is developed to overcome the disadvantages of SMCII method which overestimate runoff in low storage/or shallow soils. The SMI method allows the retention parameter to vary with accumulated plant evapotranspiration and was found to overcome the disadvantage of SMCII method. Full description for runoff estimation methods by using curve number approaches in SWAT can be found in $[1,7,11-13]$.

In the present study, inverse modeling (IM) was used for the calibration and validation of SWAT model. Sequential uncertainty fitting algorithm (SUFI-2) was used for uncertainty analysis by considering all sources of uncertainties, namely, uncertainty in driving variables, conceptual model, and parameters and measured data. Two indices were used to measure uncertainty, namely, $R$-factor and $P$-factor. The $R$ factor is the mean thickness of the $95 \%$ prediction uncertainty (95PPU) band and the $P$-factor is the percentage of measured data within $95 \%$ prediction uncertainty. Theoretically, the value for $R$-factor lies between 0 and infinity, while $P$-factor ranges between $0 \%$ and $100 \%$. If the $P$-factor is equal to $100 \%$ and the $R$-value is 0 , it is considered that the simulation exactly matches the observed data [28-30]. In addition to $R$ factor and $P$-factor, accuracy of SWAT model was evaluated by using Nash-Sutcliffe (NS) coefficient and Root Mean Square Error as given in (4) and (5), respectively, as follows:

$$
\begin{aligned}
& \mathrm{NS}=1-\left\{\frac{\sum_{i}^{n}\left(Q_{\mathrm{sim} i}-Q_{\mathrm{obsi}}\right)^{2}}{\sum_{i}^{n}\left(Q_{\mathrm{obs} i}-Q_{\mathrm{avg}}\right)^{2}}\right\}, \\
& \mathrm{RMSE}=\sqrt{\frac{\sum_{i=1}^{n}\left(Q_{\mathrm{sim} i}-Q_{\mathrm{obsi}}\right)^{2}}{n},}
\end{aligned}
$$

where $n$ is the number of time steps, $Q_{\text {simi }}$ and $Q_{\text {obsi }}$ are the simulated and the observed stream flows, respectively, at time step $i$, and $Q_{\text {avg }}$ is the average observed stream flow over the simulation period. Usually, if the value of the NashSutcliffe coefficient is more than 50\%, the SWAT model can be accepted [3].

The study area known as the Roodan watershed is located in the south of Iran between Hormozgan and Kerman Provinces. The area of catchment is $10570 \mathrm{~km}^{2}$, and it lies between the northern geographical latitude of $26^{\circ} 57^{\prime}$ to $28^{\circ} 31^{\prime}$ and the eastern longitude of $56^{\circ} 47^{\prime}$ to $57^{\circ} 54^{\prime}$. The location of the study area in Iran is shown in Figure 1. The average annual precipitation of the study area is $215 \mathrm{~mm}$. Most of the precipitation occurs between October and March, and no substantial amount of precipitation occurs during the warm months. The predominant soil type is a heterogeneous mix of clay, silt, and sand in the northern and center parts of the watershed, whereas the soils at the southern and eastern part are mostly silt and clay. According to the reports of an agricultural organization of the Hormozgan Province of Iran, approximately $30 \%$ area of the Roodan watershed is covered with low-storage soil, which is commonly a mixture of sand and silt [31]. The mechanical compositions of different types of soil and their coverage in Roodan watershed are given in Table 1. Some important and dominating land covers of the Roodan watershed are shrub land (range brush) and a mixture of grassland with shrub land.

SWAT requires the following data for runoff modeling: (1) digital elevation map (DEM); (2) land-use map; (3) soil map; and (4) meteorological data. In the present study, DEM was prepared from 1:25000 topographic maps with a resolution of $90 \mathrm{~m}$. A technique known as digital burning of river network [32] was applied on the DEM for the delineation of subbasins. Smallest subbasins cover around 3 to $4 \%$ of the total watershed area. The soil map was obtained from the global soil map archives of the Food and Agriculture Organization (FAO) of the United Nations. Land-use information of Roodan was prepared from a Landsat-7 image in conjunction with an available land-use map $(1: 25000)$ and statistical records provided by the agricultural organization of Hormozgan Province. Daily precipitation and temperature data for the period 1988-2008 were collected from a local meteorological station. Potential evapotranspiration was calculated by using the Hargreaves method.

In the present study, 26 parameters of SWAT having important roles in the estimation of daily stream flow were used for sensitivity analysis [33]. First, the sensitivity analysis was performed by using the Latin hypercube-one-factor-attime (LH-OAT) method before the calibration of the model. 


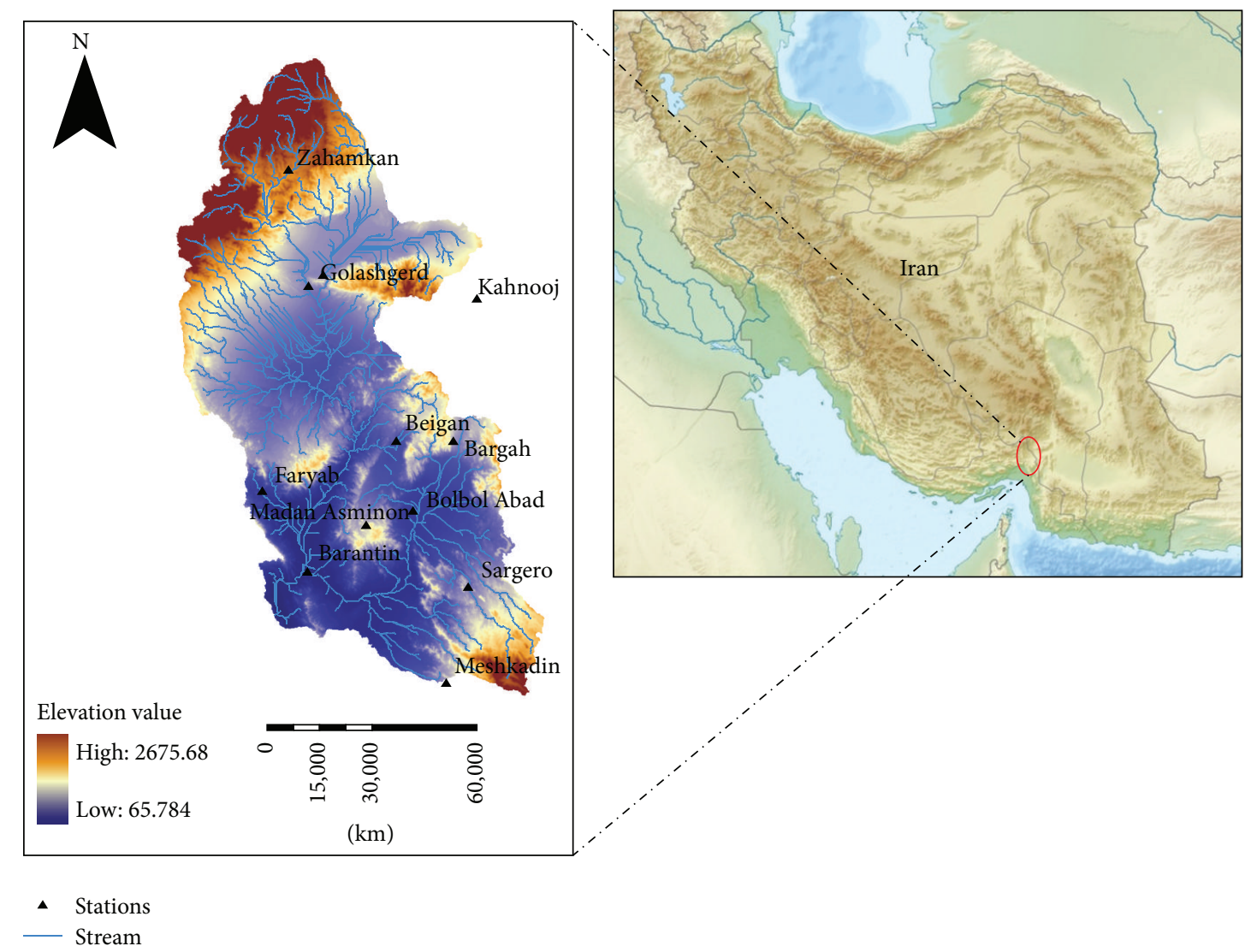

FIGURE 1: Visualization of meteorological stations and Roodan location.

Details of LH-OAT method can be found in [34]. Next, the SUFI-2 algorithm was used for uncertainty analysis. Data from 1996 to 2002 were used for calibration, and data from 2003 to 2007 were used for validation. SWAT is a continuous stream flow simulator and, therefore, it requires continuous data. Uncertainty in model simulation is supposed to increase if one or more years are excluded during model calibration or validation. Therefore, continuous daily time series data over the time period 1996-2007 was used for the study.

\section{Result and Discussion}

Table 2 shows the sensitive parameters for the SMI and SMCII methods in Roodan watershed obtained by using SUFI-2 algorithm. The research outcomes showed that the effective hydraulic conductivity of the main channel was the most sensitive parameter for both SMI and SMCII methods. This might be due to arid climate of the catchment. The aridity in climate results in many transmission losses, which are related to the effective hydraulic conductivity.

It can be seen from Table 2 that the parameters related to soil, such as soil evaporation compensation factor and soil conductivity, do not have any notable significance in the SMI method because the method is based on plant evapotranspiration and antecedent climate. In contrast, the plant evaporation compensation factor does not have any substantial impact on the SMCII method. This is due to the fact that SMCII method calculates runoff based on landuse/land-cover and soil-texture characteristic. Previously, it was reported by Kannan et al. [35] that the most sensible parameters are minimum depth of water in soil for base flow to occur, the groundwater reevaporation coefficient, and the threshold depth of water in the shallow aquifer for percolation to the deep aquifer. Amatya and Jha [17] and Williams et al. [13] found the most sensitive parameters to be soil evaporation compensation factor, plant evaporation compensation factor, curve number, manning coefficient for channel, surface runoff lag coefficient, and maximum canopy index. These findings collaborate to the results obtained in the present study.

Table 3 shows the values of the RMSE and NS coefficients obtained during calibration and validation of the model using SMCII and SMI methods. Comparison between the SMCII and SMI methods in simulating daily stream flow showed that the SMCII performed better than SMI. The RMSE was 50.2 during calibration and 36.2 during validation for SMI, and it was 36.9 during calibration and 27.6 during validation for SMCII. According to the obtained values of Nash-Sutcliff coefficient (NS) [36], the performance of SMI methods in simulating daily stream flow can be classified as fair during calibration and good during validation. On the other hand, the performance of SMCII method can be classified as good during both calibration and validation. Amatya and Jha [17] developed a daily flow simulation model by using SWAT 
TABLE 2: Sensitivity ranking of parameters for SMI and SMCII methods derived by SUFI-2 algorithm.

\begin{tabular}{|c|c|c|}
\hline \multirow{2}{*}{ Parameter } & \multicolumn{2}{|c|}{ Sensitivity rank } \\
\hline & SMI & SMCII \\
\hline $\begin{array}{l}\text { Effective hydraulic conductivity of main } \\
\text { channel }\end{array}$ & 1 & 1 \\
\hline Base flow alpha factor & - & 2 \\
\hline $\begin{array}{l}\text { SCS runoff curve number for mixing } \\
\text { grassland and shrub land based on } \\
\text { SMI/SMCII }\end{array}$ & 2 & 4 \\
\hline Manning coefficient for channel & 3 & 11 \\
\hline $\begin{array}{l}\text { SCS runoff curve number for shrub land } \\
\text { based on SMI/SMCII }\end{array}$ & 4 & 3 \\
\hline Surface runoff lag coefficient & 5 & 7 \\
\hline $\begin{array}{l}\text { Maximum canopy index for mixing } \\
\text { grassland shrub-land for SMI/maximum } \\
\text { canopy index for SMCII }\end{array}$ & 6 & 10 \\
\hline $\begin{array}{l}\text { Threshold depth of water in the shallow } \\
\text { aquifer required for return flow to occur }\end{array}$ & 7 & 8 \\
\hline Reach of evaporation coefficient & 8 & - \\
\hline $\begin{array}{l}\text { Threshold depth of water in the shallow } \\
\text { for percolation to the deep aquifer for } \\
\text { SMI/groundwater recharge to deep } \\
\text { aquifer for SMCII }\end{array}$ & 9 & 12 \\
\hline Plant evaporation compensation factor & 10 & - \\
\hline Soil available water capacity & 11 & 5 \\
\hline Soil conductivity & 12 & 9 \\
\hline Deep aquifer percolation fraction & 13 & - \\
\hline Soil evaporation compensation factor & 14 & 6 \\
\hline
\end{tabular}

TABLE 3: Values of the indices used for the evaluation of the models' accuracy during model calibration and validation.

\begin{tabular}{lcc}
\hline \multirow{2}{*}{ Index analysis } & \multicolumn{2}{c}{ Calibration-validation } \\
& SMI method & SMCII method \\
\hline NS & $0.40-0.51$ & $0.66-0.71$ \\
RMSE $\left(\mathrm{m}^{3} / \mathrm{s}\right)$ & $50.2-36.2$ & $36.9-27.6$ \\
$P$-factor & $0.57-0.5$ & $0.5-0.5$ \\
$R$-factor & $0.16-0.06$ & $0.18-0.17$ \\
\hline
\end{tabular}

with the SMI method for estimating the retention parameter in a large forested watershed in Turkey and reported NS coefficients of 0.59 and 0.7 during model calibration and validation, respectively. In comparison to their results, the NS coefficients obtained for Roodan watershed can be considered promising for an arid region. Since the $P$-factor should be near to $100 \%$ and the $R$-factor should be close to zero [30], it can be concluded that the performances of both the SMCII and SMI methods are acceptable in accordance with model uncertainty in prediction. It appears that SMI had slightly better values for the uncertainty factors $(P$ and $R$ ). The reason might be better prediction of low flows (near zero) by this method. The Roodan watershed includes mostly intermittent or ephemeral flows. Therefore, better adjustment

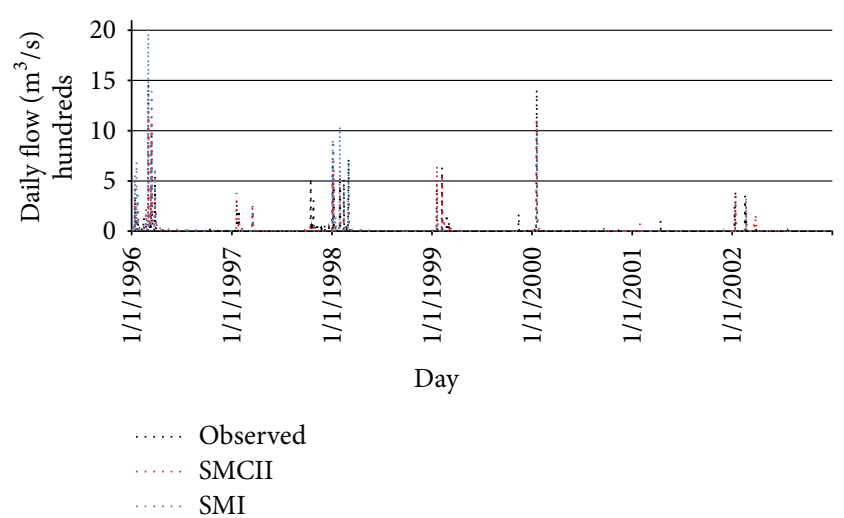

FIGURE 2: Daily observed and simulated stream flow $\left(\mathrm{m}^{3} / \mathrm{s}\right)$ by SMI and SMCII methods during model calibration.

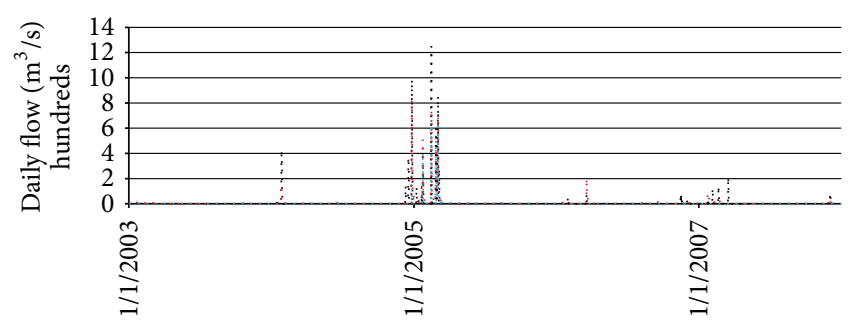

Day

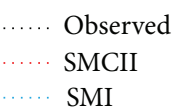

FIGURE 3: Daily observed and simulated stream flow $\left(\mathrm{m}^{3} / \mathrm{s}\right)$ by SMI and SMCII methods during model validation.

for low flows resulted in better simulation and consequently less uncertainty for SMI.

Figures 2 and 3 show observed and predicted stream flow obtained by using the SMI and SMCII methods in the Roodan watershed during model calibration and validation, respectively. The results show that SMI method overestimated and SMCII method underestimated peak stream flow during calibration. The largest event during calibration was on March 1, 1996 (observed $\left.=1462 \mathrm{~m}^{3} / \mathrm{s}\right)$, which was estimated by SMI as $2018 \mathrm{~m}^{3} / \mathrm{s}$ and SMCII as $1193 \mathrm{~m}^{3} / \mathrm{s}$. On the other hand, both methods underestimated the largest peak flow during the validation period (in February 2005, observed $=$ $1248.5 \mathrm{~m}^{3} / \mathrm{s}$, SMI $=664.7 \mathrm{~m}^{3} / \mathrm{s}$, and SMCII $=746.5 \mathrm{~m}^{3} / \mathrm{s}$ ). It can be speculated that the SMI method is sensitive to the amount of precipitation and the area of low-storage or shallow soils. It can be noted that about $30 \%$ of the area of the Roodan watershed has low-storage soil, and the annual rainfall is less than $250 \mathrm{~mm}$. However, SMCII still was found to provide better results. This may be due to the lower percentage of low-storage soil in the Roodan watershed, or it may be possible that the low-storage soil only has an impact on runoff for a brief period of time.

Figures 4 and 5 show the cumulative daily stream flow obtained by using the SMI and SMCII methods during 


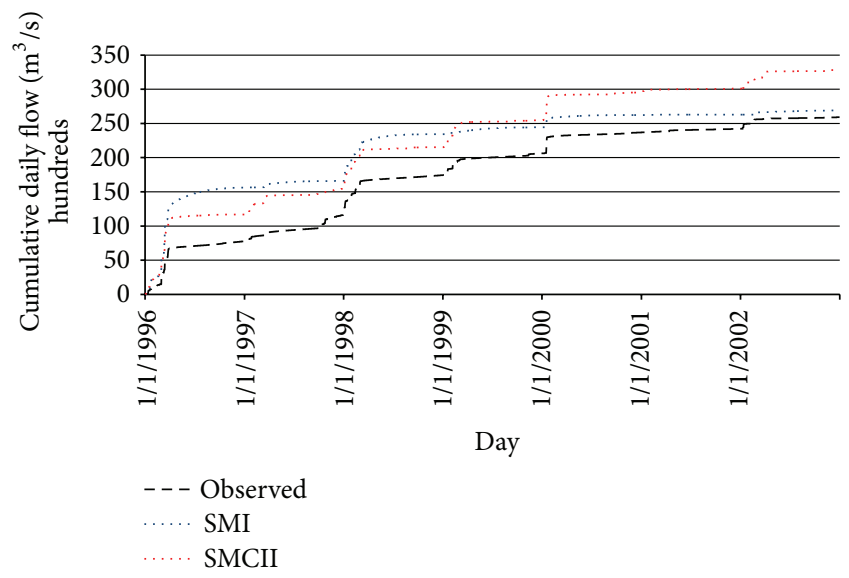

FIGURE 4: Predicted cumulative daily discharge by SMI and SMCII methods against observed cumulative daily discharge during calibration.

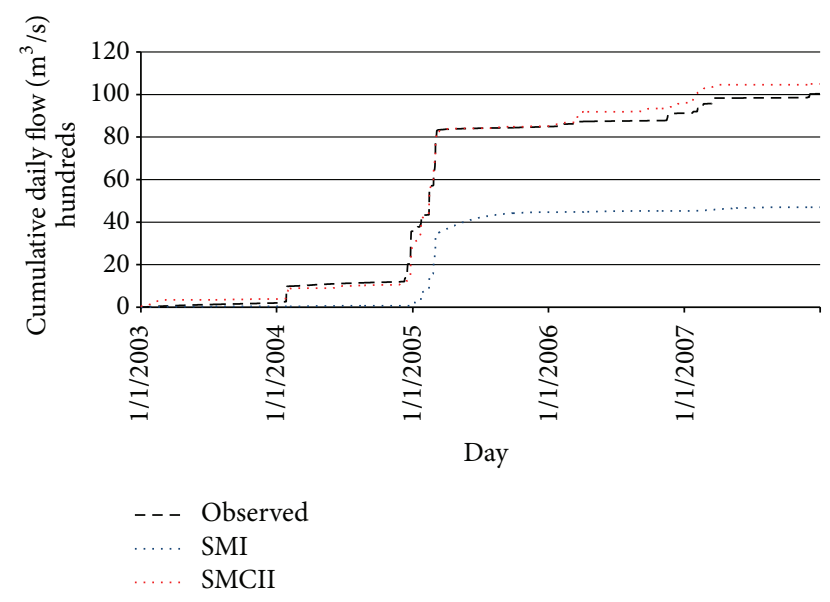

FIGURE 5: Predicted cumulative daily discharge by SMI and SMCII methods against observed cumulative daily discharge during validation.

model calibration and validation, respectively. Generally, the cumulative flow graph helps in estimating runoff for watershed planning or management. Figure 4 shows that the SMI method estimated closer cumulative discharge compared to SMCII method at the end of calibration period (1996-2002). The SMCII method showed that the trend of the fluctuation of the cumulative discharge was in better agreement with the observed data (Figure 4). On the other hand, SMCII showed overestimation for cumulative discharge.

Figure 5 shows the underestimation of cumulative flow by SMI method and overestimation by SMCII method during model validation. The SMCII was found to provide excellent prediction of cumulative stream flow for the period of 20032006. During the rest of the validation period (2006-2007), SMCII was found to yield slight overestimations. On the other hand, SMI method underestimated the cumulative discharge seriously during model validation, especially from 2005 to 2007.
TABLE 4: Analysis of stream flow $\left(\mathrm{m}^{3} / \mathrm{s}\right)$ percentiles during model validation.

\begin{tabular}{lccccccc}
\hline & \multicolumn{7}{c}{ Percentiles } \\
& 5 & 10 & 25 & 50 & 75 & 90 & 95 \\
\hline Observed & 0.04 & 0.07 & 0.21 & 0.43 & 0.63 & 1 & 2 \\
SMI & 0.0 & 0.0 & 0.01 & 0.13 & 0.57 & 3.1 & 5.8 \\
SMCII & 0.0 & 0.0 & 0.0 & 0.06 & 1.1 & 8.1 & 15.6 \\
\hline
\end{tabular}

TABLE 5: Comparison of maximum flow predicted by SMI and SMCII methods during model validation.

\begin{tabular}{lcccc}
\hline $\begin{array}{l}\text { Stream flow }>500 \\
\left(\mathrm{~m}^{3} / \mathrm{s}\right)\end{array}$ & SMI & SMCII & \multicolumn{2}{c}{ Relative error* $\%$} \\
SMI & SMCII \\
\hline 985 & 118 & 824 & 88.0 & $\mathbf{1 6 . 3}$ \\
527.5 & 21 & 366.6 & 96.1 & $\mathbf{3 0 . 5}$ \\
1284.5 & 665 & 746.5 & 46.8 & $\mathbf{4 0 . 2}$ \\
596 & 500 & 434.6 & $\mathbf{1 6 . 1}$ & 27 \\
854 & 680 & 703.2 & 20.4 & $\mathbf{1 7 . 6}$ \\
\hline
\end{tabular}

${ }^{*}$ Negative values are overestimations, and positive values are underestimations.

Kannan et al. [12] assessed the performance of SMCII and SMI methods in the catchments of the United States where the average annual rainfall was $292 \mathrm{~mm}$ and found that the SMI method underestimated the stream flow. They concluded that the SMI method is not as capable as the SMCII method in simulating stream flow in low precipitation catchments; this is in agreement with the finding of present study. Figure 5 also shows that the SMI method predicted stabilization of cumulative stream flow at the end of validation period. This may be due to more sensitivity of SMI model to climate and the amount of area that is covered by low-storage soil in a catchment.

Table 4 illustrates the percentile analysis of stream flow during model validation. It can be seen from the table that the SMI method yields closer values for percentile of stream flow during model validation. For 25 or less percentile data, both SMI and SMCII were found to predict similar stream flow values. Amatya and Jha [17] also reported that SWAT could simulate low stream flows (near zero) in a forested catchment. This means that the forested area in the catchment improves the predictions for the low flows by SWAT. For 50 percentile (value of median), SMI had fair agreement with the observed data in comparison with the SMCII method.

Finally, the behavior of the SMI and SMCII methods is assessed by analyzing the relative errors (\%) for stream flow exceeding $500 \mathrm{~m}^{3} / \mathrm{s}$ during model validation (Table 5 ). The table shows that SMCII yielded lower relative errors for high stream flows during model validation. On the other hand, both methods were found to underestimate the highest discharge during model validation. Both methods also displayed an underestimation trend for flow that exceeded $500 \mathrm{~m}^{3} / \mathrm{s}$. Table 6 presents the general statistics of stream flows during model validation. The SMI method underestimated the mean flow (observed $=5.4 \mathrm{~m}^{3} / \mathrm{s}$, SMI $=2.5 \mathrm{~m}^{3} / \mathrm{s}$, and SMCII $=$ $5.7 \mathrm{~m}^{3} / \mathrm{s}$ ). This may be due to the inherent characteristics of 
TABLE 6: General statistics of observed and simulated stream flow by using SMI and SMCII methods during model validation (2003-2008).

\begin{tabular}{|c|c|c|c|c|c|}
\hline Type of flow & $\begin{array}{l}\text { Mean } \\
\left(\mathrm{m}^{3} / \mathrm{s}\right)\end{array}$ & $\begin{array}{c}95 \% \text { confidence } \\
\text { interval for mean } \\
\mathrm{m}^{3} / \mathrm{s} \\
\text { (lower-upper) }\end{array}$ & $\begin{array}{l}\text { Standard } \\
\text { deviation }\end{array}$ & Minimum-maximum $\left(\mathrm{m}^{3} / \mathrm{s}\right)$ & Range $\left(\mathrm{m}^{3} / \mathrm{s}\right)$ \\
\hline Observed flow & 5.4 & $3.1-7.8$ & 52 & $0.03-1248.5$ & 1248.47 \\
\hline Simulated flow by SMI & 2.5 & $1.2-3.8$ & 28.5 & $0-680$ & 680 \\
\hline Simulated flow by SMCII & 5.7 & $3.9-7.5$ & 39.1 & $0-824$ & 824 \\
\hline
\end{tabular}

the SMI method that offset high predictions of stream flow. In general, the SMCII method was more promising than those of the SMI method. However, SMI showed better estimation for low flows.

\section{Conclusions}

Two approaches of curve number generation embedded in the SWAT model were discussed for hydrologic prediction. The first was the Soil Moisture index (SMI), which is based on previous meteorological conditions, and the second was the Soil Moisture Condition II (SMCII), which is based on soil features. The study showed that the SMI method relies mostly on previous climate conditions. It does not account for soil features in the catchment in accordance with the sensitivity of related parameters. However, the SMCII method is highly sensitive to soil features. The present study showed that both SMI and SMCII methods can predict daily steam flow with reasonable accuracy; however, SMCII showed better total performance for flow prediction. However, low flows were modeled better via the SMI method in SWAT. The results suggested that the results of the SMI method can be affected by the amount of area in a catchment that has low-storage soils. Regional climate also might be an important factor that determines the performance of the SMI method. Therefore, moderately accurate simulation of stream flows was by the SMI method for flows greater than 50 percentile (value of median). Statistical evaluation showed that the SMCII yielded better values in simulating average flow during calibration and validation. It can be suggested that the performance of SMI and SMCII methods should be analyzed in other arid catchments with low-storage soil coverage for better assessment of these methods in an arid region. Also, there is a need to conduct additional evaluations to explore the behavior of the SMI and SMCII methods in various regional climates.

\section{Conflict of Interests}

The authors declare that there is no conflict of interests regarding the publication of this paper.

\section{Acknowledgments}

The authors sincerely appreciate the Research Management Center (RMC) of Universiti Teknologi Malaysia for funding them to carry out this research under postdoctoral fellowship scheme as well as through university research Grant (vot no. Q.J130000.2522.06H36). The authors are thankful to all members of Consultant Engineers of Ab Rah Saz Shargh Corporation in Iran and the Regional Water Organization, Agricultural Organization, and Natural Resources Organization of Hormozgan Province, Iran.

\section{References}

[1] S. L. Neitsch, J. G. Arnold, J. R. Kiniry, R. Srinvasan, and J. R. Williams, "Soil and water assessment tool, input/output file documentation, version 2009," Texas Water Resources Institute Technical Report No. 365, Soil and Water Research Laboratory, Agricultural Research Service, and Blackland Research Center, Texas Agrilife Research, Texas A\&M University, College Station, Tex, USA, 2010.

[2] Z. Huang, B. Xue, and Y. Pang, "Simulation on stream flow and nutrient loadings in Gucheng Lake, Low Yangtze River Basin, based on SWAT model," Quaternary International, vol. 208, no. 1-2, pp. 109-115, 2009.

[3] C. Oeurng, S. Sauvage, and J. M. Sánchez-Pérez, "Assessment of hydrology, sediment and particulate organic carbon yield in a large agricultural catchment using the SWAT model," Journal of Hydrology, vol. 401, no. 3-4, pp. 145-153, 2011.

[4] J. Chen, X. Li, and M. Zhang, "Simulating the impacts of climate variation and land-cover changes on basin hydrology: a case study of the Suomo basin," Science in China, Series D: Earth Sciences, vol. 48, no. 9, pp. 1501-1509, 2005.

[5] V. Krysanova and J. G. Arnold, "Advances in ecohydrological modelling with SWAT-a review," Hydrological Sciences Journal, vol. 53, no. 5, pp. 939-947, 2008.

[6] US Department of Agriculture and Natural Resources Conservation Service (USDA-NRCS), Part 630: Hydrology. National Engineering Handbook, 2004.

[7] N. W. Kim, J. W. Lee, J. Lee, and J. E. Lee, "SWAT application to estimate design runoff curve number for South Korean conditions," Hydrological Processes, vol. 24, no. 15, pp. 21562170, 2010 .

[8] D. E. Woodward, R. H. Hawkins, and Q. D. Quan, "Curve number method: origins, applications and limitations. Hydrologic modeling for the 21st century," in Proceedings of the 2nd Federal Interagency Hydrologic Modeling Conference, Las Vegas, Nev, USA, 2002.

[9] J. P. Patil, A. Sarangi, A. K. Singh, and T. Ahmad, "Evaluation of modified CN methods for watershed runoff estimation using a GIS-based interface," Biosystems Engineering, vol. 100, no. 1, pp. 137-146, 2008. 
[10] Soil Conservation Service Engineering Division, Urban Hydrology for Small Watersheds, Technical Release 55, U.S. Department of Agriculture, 1986.

[11] S. L. Neitsch, J. G. Arnold, J. R. Kiniry, and J. R. William, Soil and Water Assessment Tool Theoretical Documentation Version 2005, Grassland, Soil and Water Research Laboratory, Agricultural Research Service, and Blackland Research Center, Texas Agricultural Experiment Station, Temple, Tex, USA, 2005.

[12] N. Kannan, C. Santhi, J. R. Williams, and J. G. Arnold, "Development of a continuous soil moisture accounting procedure for curve number methodology and its behaviour with different evapotranspiration methods," Hydrological Processes, vol. 22, no. 13, pp. 2114-2121, 2008.

[13] J. R. Williams, N. Kannan, X. Wang, C. Santhi, and J. G. Arnold, "Evolution of the scs runoff curve number method and its application to continuous runoff simulation," Journal of Hydrologic Engineering, vol. 17, no. 11, pp. 1221-1229, 2012.

[14] E. D. White, Z. M. Easton, D. R. Fuka et al., "Development and application of a physically based landscape water balance in the SWAT model," Hydrological Processes, vol. 25, no. 6, pp. 915-925, 2011.

[15] Z. M. Easton, D. R. Fuka, M. T. Walter, D. M. Cowan, E. M. Schneiderman, and T. S. Steenhuis, "Re-conceptualizing the soil and water assessment tool (SWAT) model to predict runoff from variable source areas," Journal of Hydrology, vol. 348, no. 3-4, pp. 279-291, 2008.

[16] N. W. Kim and J. Lee, "Temporally weighted average curve number method for daily runoff simulation," Hydrological Processes, vol. 22, no. 25, pp. 4936-4948, 2008.

[17] D. M. Amatya and M. K. Jha, "Evaluating the SWAT model for a low-gradient forested watershed in coastal South Carolina," The American Society of Agricultural and Biological Engineers, vol. 54, no. 6, pp. 2151-2163, 2011.

[18] G. Ghaffari, S. Keesstra, J. Ghodousi, and H. Ahmadi, "SWATsimulated hydrological impact of land-use change in the Zanjanrood Basin, Northwest Iran," Hydrological Processes, vol. 24, no. 7, pp. 892-903, 2010.

[19] G. Ghaffari, "The impact of DEM resolution on runoff and sediment modeling results," Research Journal of Environmental Sciences, vol. 5, pp. 691-702, 2011.

[20] M. Faramarzi, K. C. Abbaspour, R. Schulin, and H. Yang, "Modelling blue and green water resources availability in Iran," Hydrological Processes, vol. 23, no. 3, pp. 486-501, 2009.

[21] R. Rostamian, A. Jaleh, M. Afyuni et al., "Application of a SWAT model for estimating runoff and sediment in two mountainous basins in central Iran," Hydrological Sciences Journal, vol. 53, no. 5, pp. 977-988, 2008.

[22] S. Akhavan, J. Abedi-Koupai, S.-F. Mousavi, M. Afyuni, S.-S. Eslamian, and K. C. Abbaspour, "Application of SWAT model to investigate nitrate leaching in Hamadan-Bahar Watershed, Iran," Agriculture, Ecosystems and Environment, vol. 139, no. 4, pp. 675-688, 2010.

[23] I. Masih, S. Maskey, S. Uhlenbrook, and V. Smakhtin, "Assessing the impact of areal precipitation input on stream flow simulations using the SWAT model," Journal of the American Water Resources Association, vol. 47, no. 1, pp. 179-195, 2011.

[24] I. Masih, S. Maskey, S. Uhlenbrook, and V. Smakhtin, "Impact of upstream changes in rain-fed agriculture on downstream flow in a semi-arid basin," Agricultural Water Management, vol. 100, no. 1, pp. 36-45, 2011.
[25] K. C. Abbaspour, M. Faramarzi, S. S. Ghasemi, and H. Yang, "Assessing the impact of climate change on water resources in Iran," Water Resources Research, vol. 45, no. 10, Article ID W10434, 2009.

[26] M. Jajarmizdeh, S. Harun, B. Ghahraman, and M. H. Mokhtari, "Modeling daily stream flow using plant evapotranspiration method," International Journal of Water Resources and Environmental Engineering, vol. 4, no. 6, pp. 218-226, 2012.

[27] M. Jajarmizdeh, S. Harun, R. Abdullah, and M. Salarpour, "An evaluation of blue water prediction in southern part of Iran using SWAT," Environmental Engineering and Management Journal. In press.

[28] K. C. Abbaspour, M. T. van Genuchten, R. Schulin, and E. Schläppi, "A sequential uncertainty domain inverse procedure for estimating subsurface flow and transport parameters," Water Resources Research, vol. 33, no. 8, pp. 1879-1892, 1997.

[29] K. C. Abbaspour, C. A. Johnson, and M. T. van Genuchten, "Estimating uncertain flow and transport parameters using a sequential uncertainty fitting procedure," Vadose Zone Journal, vol. 3, no. 4, pp. 1340-1352, 2004.

[30] K. C. Abbaspour, J. Yang, I. Maximov et al., "Modelling hydrology and water quality in the pre-alpine/alpine Thur watershed using SWAT," Journal of Hydrology, vol. 333, no. 2-4, pp. 413430, 2007.

[31] A. R. S. Shargh, Comprehensive Studies of Water Resource Management for Roodan Watershed, Register Code 14800, Consulting Water Resource Engineering Corporation, Mashhad, Iran, 2009.

[32] M. Arabi, R. S. Govindaraju, M. M. Hantush, and B. A. Engel, "Role of watershed subdivision on modeling the effectiveness of best management practices with SWAT," Journal of the American Water Resources Association, vol. 42, no. 2, pp. 513-528, 2006.

[33] M. Winchell, R. Srinivasan, M. di Luzio, and J. Arnold, ArcSWAT Interface for SWAT2009 Users' Guide, Grassland, Soil and Water Research Laboratory, Agricultural Research Service,and Blackland Research Center, Texas Agricultural Experiment Station, Temple, Tex, USA, 2010.

[34] A. van Griensven, T. Meixner, S. Grunwald, T. Bishop, M. Diluzio, and R. Srinivasan, "A global sensitivity analysis tool for the parameters of multi-variable catchment models," Journal of Hydrology, vol. 324, no. 1-4, pp. 10-23, 2006.

[35] N. Kannan, S. M. White, F. Worrall, and M. J. Whelan, "Sensitivity analysis and identification of the best evapotranspiration and runoff options for hydrological modelling in SWAT-2000," Journal of Hydrology, vol. 332, no. 3-4, pp. 456-466, 2007.

[36] P. B. Parajuli, N. O. Nelson, L. D. Frees, and K. R. Mankin, "Comparison of AnnAGNPS and SWAT model simulation results in USDA-CEAP agricultural watersheds in south-central Kansas," Hydrological Processes, vol. 23, no. 5, pp. 748-763, 2009. 

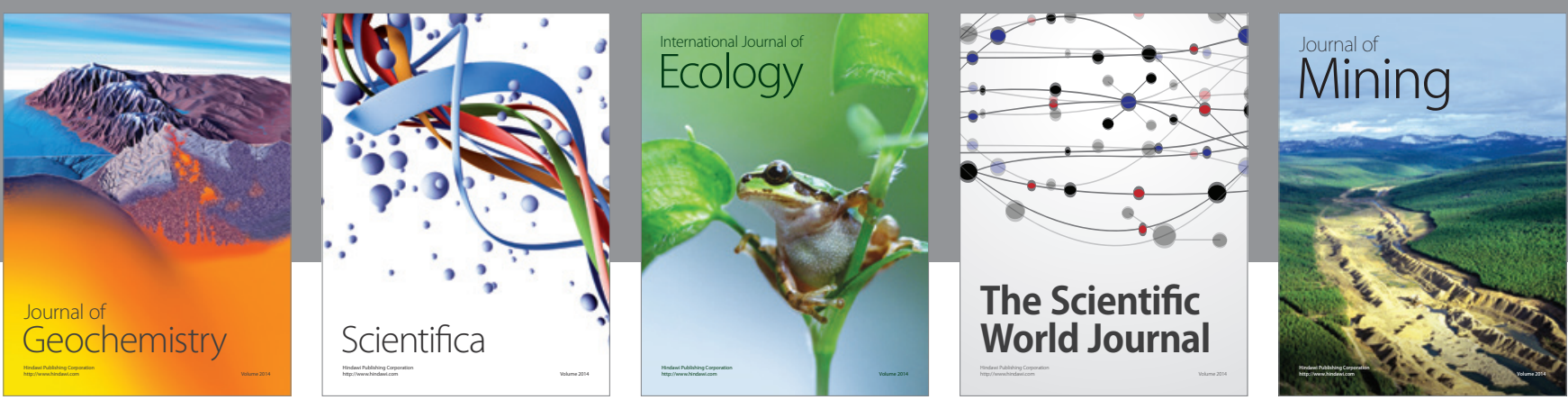

The Scientific World Journal
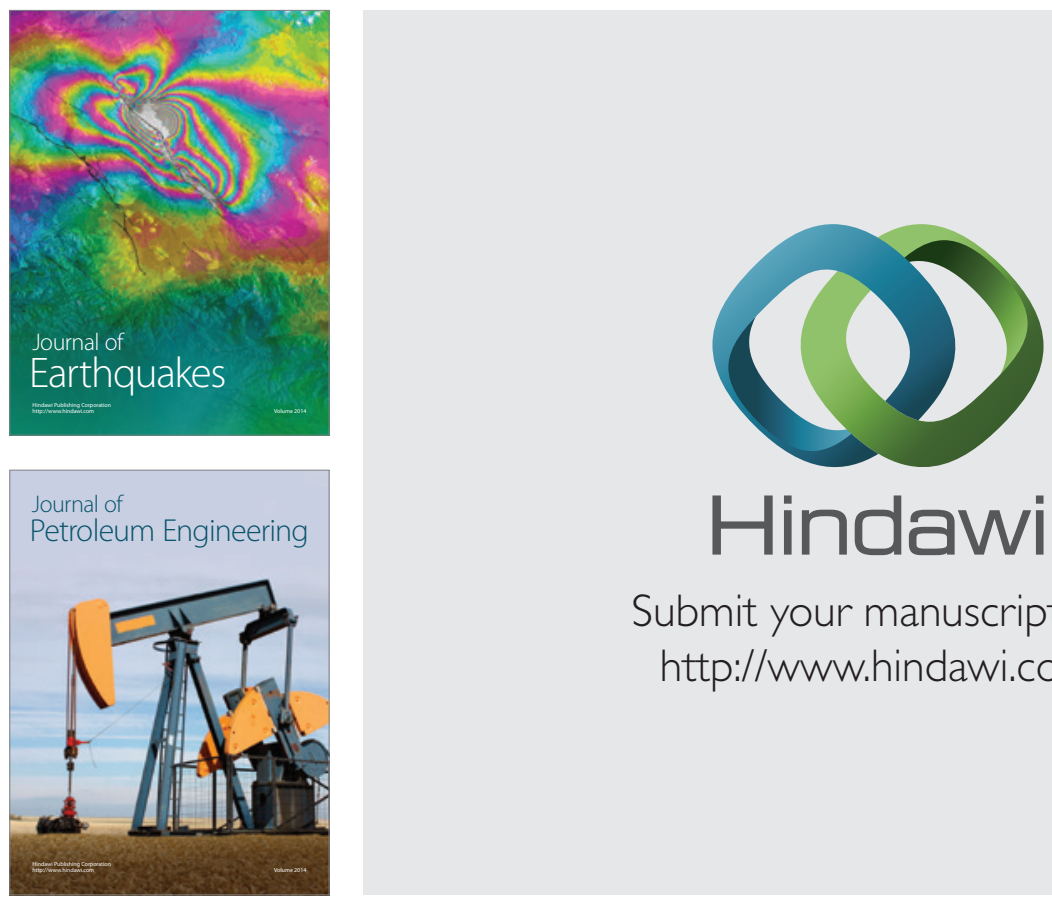

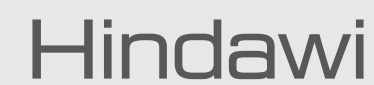

Submit your manuscripts at

http://www.hindawi.com
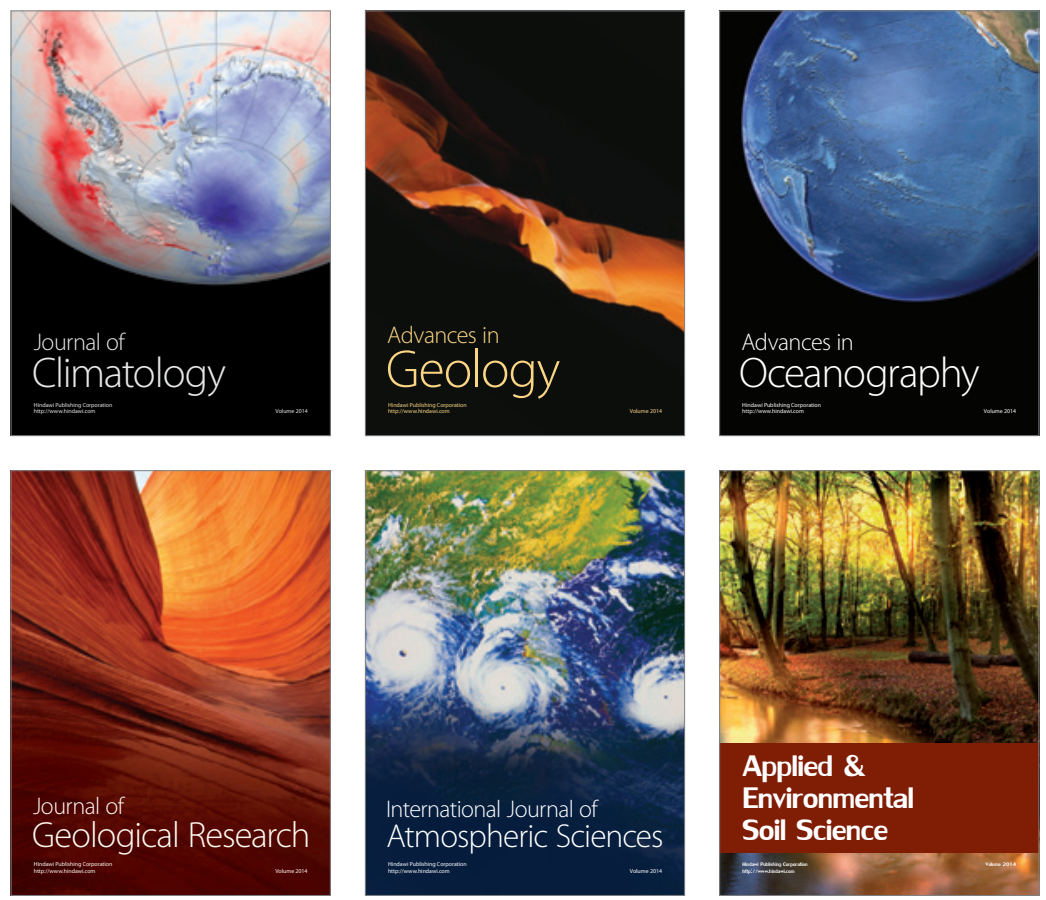
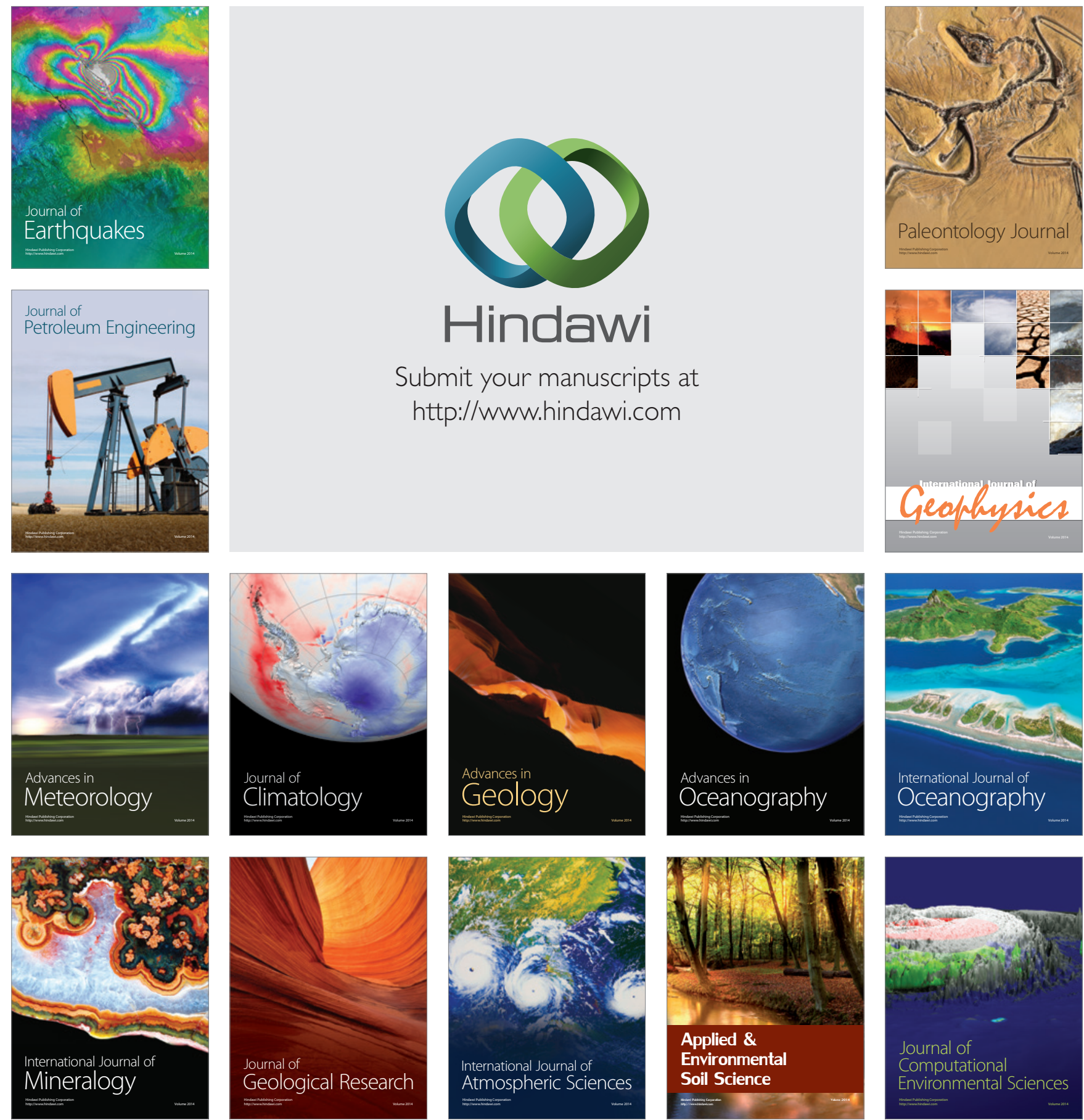